\title{
Resolving the market mysteries of medical isotopes
}

$\mathrm{F}$ or nearly four decades, antinuclear activists have called for limits on the use of highly enriched uranium (HEU) in civilian installations around the world. Although Iran and North Korea might be among the obvious targets of that movement, so too has been the National Research Universal (NRU) reactor in Chalk River, Ontario, which produces medical isotopes using the potential bomb-making material.

Yet, so vital has the output of the reactor been that Canada was able to earn a special exemption from a 1992 American law that compelled foreign reactors to commit to convert to lowenriched uranium (LEU) as expeditiously as possible if they wanted to access HEU fuel from the United States to use in their reactors. To that end, the US established a Reduced Enrichment for Research Test Reactors program to develop LEU for foreign reactors, which ultimately morphed into the Global Threat Reduction Initiative, which has targeted 200 reactors in the US and around the world for conversion or shutdown by 2020 . To date, 72 have converted or closed their doors.

Although there are no international prohibitions on HEU exports, there are guidelines for such traffic that were developed by the Nuclear Suppliers Group, a multinational body created in the aftermath of India's controversial nuclear test in 1974. And those who trade in the material must abide by International Atomic Energy Agency safeguards. Still, safety concerns have prompted several nations to introduce stricter export controls on HEU, much in the manner of the US "Schumer Amendment" of 1992. And now the US has launched another bid to shut down HEU exports once and for all, building on a 2009 pledge by President Barack Obama's administration to completely prohibit such traffic in nuclear-weapons usable material within a four-year period. To that end, the Americans also extracted a commitment from 47 nations at the Nuclear Security Summit in 2010 to actively pursue HEU reduction efforts.

In support of that long-term goal, the White House indicated in June that

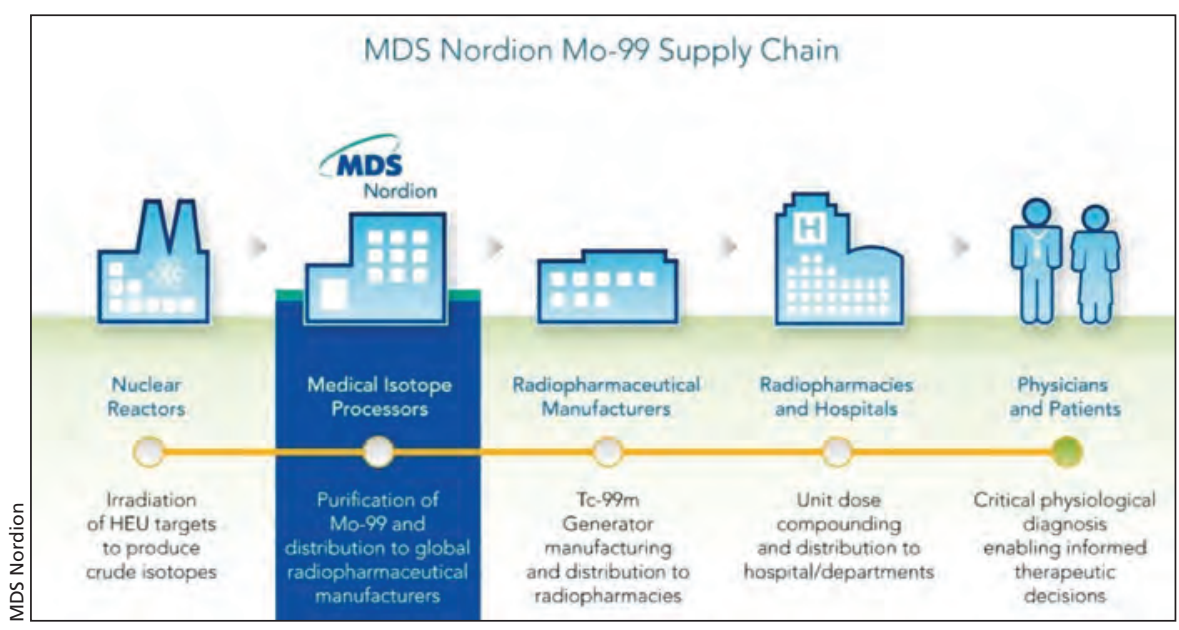

Canada's medical isotope supply chain. If the National Research Universal reactor is not converted before highly enriched uranium fuel becomes unavailable from American sources, Canada will be obliged to obtain molybdenum from alternative sources.

it would be moving with preferential procurement of medical radioisotopes produced without the use of HEU. As it takes about five times more LEU to make the same volume of isotopes using HEU, raising the cost for producers and ultimately, the users of medical isotopes, the Obama administration indicated that some manner of compensation would be provided to imaging centres that used isotopes produced through LEU (www.white house.gov/the-press-office/2012/06/07 /fact-sheet-encouraging-reliable-supplies -molybdenum-99-produced-without-).

US plans were further clarified in mid-July, when 2013 funding rules were proposed by the US Department of Health and Human Services indicating that an additional $\$ 10$ would be paid for pharmaceutical products derived from "non-HEU methods." More specifically, a new billing code would specifically recognize non-HEU source technetium - the workhorse isotope used in singlephoton emission computed tomography imaging — and provide the extra money for each dose administered.

Where does all that leave poor Canada, home of the troubled NRU? It uses HEU to produce molybdenum, which decays into the medical isotope techtinium used in imaging facilities, and underwent extended shutdowns between 2007 and 2010 and is scheduled to be closed permanently in 2016 .

Many hope the long-term solution to
Canadian medical isotope needs will be medical isotopes regionally produced through the use of cyclotrons (www.cmaj .ca/lookup/doi/10.1503/cmaj.109-4217).

But hope and reality are often disparate notions and, presuming that the US actually slams the door on HEU fuel exports in 2013, there's the tiny matter of supplying the hot stuff needed to make the technetium isotope in the final years of NRU operations. Running the NRU is not the problem: all of the reactor's activities have been powered by LEU fuel since the early 1990s. But HEU is still used for the targets that are inserted into the reactor, where they are bombarded with neutrons to create the all important molybdenum isotope.

The combined realities of NRU woes and prohibitions on HEU exports also have technicians, regulators and politicians rapidly trying to get up to speed on the harsh realities of isotope production, supply and demand, and specifically, the fact that Canadian imaging needs will have to be filled with HEU obtained from other sources, or from molybdenum-producing reactors in other nations. It's exactly the kind of contingency planning that Canada was accused of thwarting in the past (www.cmaj.ca/lookup/doi/10.1503 /cmaj.080256).

In short, the shutdowns of the NRU forced Canadians to come to terms with the many mysteries of market dynamics related to isotope production. 
"When that happened, people in this department were scrambling," recalls Serge Dupont, deputy minister of Natural Resources Canada, who joined the department in 2009. "They didn't know the isotope supply chain. They didn't know who the other suppliers were. It had never been analyzed."

"We needed to have this discussion internationally," says Dupont, who turned to the Nuclear Energy Agency to help establish the High Level Group on Medical Radioisotopes, which subsequently undertook detailed economic studies of isotope production and possible strategies for ensuring a reliable global supply.

Those studies pointed out that the price of molybdenum was effectively subsidized, as the isotopes were being produced by government-owned reactors and moreover, that the cost of isotopes produced by such facilities would be less than those that used LEU fuel or those that used cyclotrons to produce isotopes.

The high level group recommended governments collaborate to raise the price of molybdenum, so as to recover the full cost of its production, including expenses related to waste disposal and reactor maintenance. In that way, isotopes produced through the use of LEU could be commercially competitive with those produced with HEU.

Fears that the move would result in a spike in the price of isotope-based imaging procedures were unjustified, Dupont notes. "It's a very small portion of the overall cost of the procedure, once you factor in all the other steps in the supply chain - the tracer drug, the gamma camera, the physician, and the overhead around all that."

The proposed American move toward preferential procurement of isotopes made with LEU is expected to further alter the economics of production. It eliminates the prospect that a new pricing regime could be undercut by highvolume, lower-cost producers using HEU, says Alan Kuperman, associate professor of public affairs with the University of Texas at Austin. Moreover, most producers are well on their way to converting their facilities to run on LEU, he says, adding that the remainder are primarily found in Russia.

Canadian isotope distributor MDS Nordion has been exploring ways of using Russian production to make up for any future isotope shortfalls in Canada, although a formal trade channel has not yet been established.

"Our supply agreement with Russian supplier JSC Isotope is aimed at providing a supplemental supply of Mo-99 [molybdenum] until 2020," the company writes in an email. "The contract provides for the parties to address LEU conversion. The timing and approach of conversion are under evaluation."

In a presentation to the Nuclear Security Summit in 2010, Nordion offered a timeline for LEU conversion, under which its Ottawa-based processing facility would be ready this year to handle LEU targets. It also indicated that JSC Isotope would likewise convert its reactor and processing facilities to LEU between 2014 and 2018 (www.invap.com.ar /en/nuclear/nuclear-security-summit/624 -nuclear-security-summit.html).

Whether or not those projections remain accurate, Kuperman insists that the latest American moves mean Nordion is running out of wiggle room for its timing and approach.

\section{More news online}

The science of pesticide-free potato chips: There is no question that the organic food industry is booming. Even junk food makers are clambering aboard the organic train, as a quick walk through the aisles of almost any supermarket demonstrates. Now available? Organic chocolate bars. Organic jelly beans. Even organic potato chips.

What was once a niche market has become such a juggernaut that Research and Markets, the Irelandbased international market research provider, projects global revenues now range in the neighbourhood of

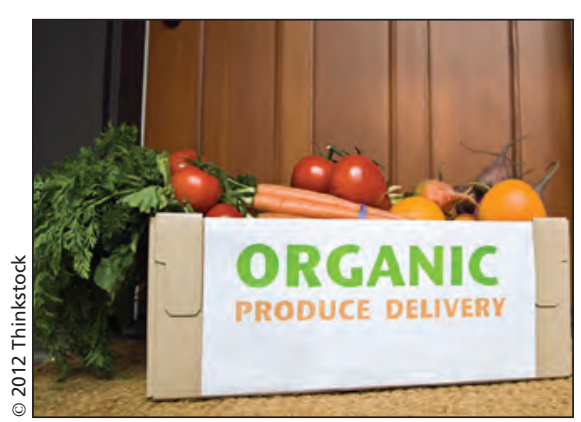

But he also questions the wisdom of such a slow timeline for LEU conversion, in light of America's apparent intention to slam its doors to the use of isotopes produced through the use of HEU. "To invest now a lot of money into producing isotopes with HEU is likely to be a huge waste something Nordion shouldn't want to do, and Nordion shareholders shouldn't want to do," he argues. "And for the record, Canada's government really shouldn't be happy about Nordion encouraging increased civilian commerce in HEU. That's counter to what the Canadian government subscribed to at the Nuclear Security Summit in 2010, a policy of HEU minimization and eventually total phase-out."

Russian reactor operators should be more than capable of converting their facilities to run on LEU, just as their European counterparts are already doing, he adds. — Tim Lougheed, Ottawa, Ont.

CMAJ 2012. DOI:10.1503/cmaj.109-4263

US\$60 billion per year, having experienced a compound annual growth rate of about $11 \%$ between 2006 and 2010 (www.researchandmarkets .com/reports/2001395/global_organic food).

Simply put, that's a whole lot of pesticide-free lettuce.

The public perception appears to be that organic foods are better, having been grown under strict conditions of purity that preclude the use toxic agricultural chemicals such as synthetic pesticides, or growth hormones or antibiotics, in the case of animals like cows and chickens. Ergo, they must be "healthier" or more nutrient rich than conventionally produced fare, or, at a very minimum, free of traces of nasty compounds.

But is there any concrete evidence in support of that proposition?

Not much, if any, according to independent experts.

Tons, according to the organic food industry and organic devotees (www .cmaj.ca/lookup/doi/10.1503/cmaj.109 -4290). - Michael Monette, CMAJ 